\title{
ANTIFUNGAL EFFICIENCY OF COPPER OXYCHLORIDE-CONJUGATED SILVER NANOPARTICLES AGAINST COLLETOTRICHUM GLOEOSPORIOIDES WHICH CAUSES ANTHRACNOSE DISEASE
}

\author{
RAGHAVENDRA SN, RAGHU HS*, DIVYASHREE K, RAJESHWARA AN
}

Department of PG Studies and Research in Biochemistry, Kuvempu University, Shankaraghatta, Karnataka, India. Email: hsr1983@gmail.com

Received: 29 May 2019, Revised and Accepted: 28 June 2019

ABSTRACT

Objectives: Anthracnose disease is caused by Colletotrichum gloeosporioides, affecting most of the fruit and vegetable plants. The present study is aimed to synthesize silver nanoparticles (AgNPs) using neem extract and conjugate then with fungicide to check the antifungal activity against anthracnose disease.

Methods: In the current study, we have synthesized copper oxychloride-conjugated AgNPs (COC-AgNPs) by a biological method using neem extract and have tested their effectiveness against C. gloeosporioides. The COC-AgNPs were characterized by UV-visible spectroscopy, fourier-transform infrared, scanning electron microscopy, and X-ray diffraction analysis, and in vitro antifungal activity was investigated.

Results: The shape of COC-AgNPs was found to be spherical with an average particle size of $21-25 \mathrm{~nm}$. The fungicide-conjugated AgNPs exhibited highest growth inhibition of C. gloeosporioides ( 187\%) as compared to fungicide copper oxychloride.

Conclusion: These results indicate that the COC-AgNPs could be effectively used to control anthracnose disease in mango and in other crops. These COC-AgNPs can drastically reduce the amount of fungicide currently used which will reduce the environmental pollution caused by the fungicide.

Keywords: Anthracnose disease, Colletotrichum gloeosporioides, Copper oxychloride, Silver nanoparticles.

(c) 2019 The Authors. Published by Innovare Academic Sciences Pvt Ltd. This is an open access article under the CC BY license (http://creativecommons. org/licenses/by/4. 0/) DOI: http://dx.doi.org/10.22159/ajpcr.2019.v12i8.34297

\section{INTRODUCTION}

Mango is a juicy drupe fruit having a place with the sort Magnifera, comprising of various tropical fruiting trees and developed for the most part for eatable organic product [1]. Mango is rich in prebiotic dietary fiber, vitamins, minerals, and polyphenolic and flavonoid antioxidant compounds [2]. However, the fruit is affected by anthracnose disease caused by Colletotrichum gloeosporioides. Anthracnose is a group of diseases that cause dark, sunken lesions on fruits, and leaves. Postharvest anthracnose appears as rounded brown to black lesions with an indefinite border on the fruit surface. These lesions are usually restricted to the peel, but in severe cases, the fungus can penetrate even the fruit pulp.

Owing to widespread applications, exploration and exploitations of silver nanomaterials are recently attracting considerable attention [3]. Silver has a wide range of biological applications, particularly in the form of nanoparticles [4]. Various biological and chemical methods are employed for the synthesis of silver nanoparticles (AgNPs). AgNPs were synthesized by chemical methods using some reducing agent such as sodium borohydride [5]. Since silver has antimicrobial properties, AgNPs conjugates can be used as antifungal/antibacterial agents.

Copper oxychloride is a common name of dicopper chloride trihydroxide. The chemical formula is $\mathrm{Cu}_{2}(\mathrm{OH})_{3} \mathrm{Cl}$. It is often referred to as tribasic copper chloride, copper trihydroxyl chloride, or copper hydroxychloride. $\mathrm{Cu}_{2}(\mathrm{OH})_{3} \mathrm{Cl}$ has been used as a fungicidal spray on tea, orange, grape, rubber, coffee, cardamom, and cotton etc., and as an aerial spray on rubber for control of phytophthora attack on leaves (Fig. 1) [6,7].

Azadirachta indica commonly known as neem belongs to the family Meliaceae and is well known in India and its neighboring countries for more than 200 years as one of the most versatile medicinal plants having a wide spectrum of biological activity [8]. This plant is used as a household remedy against both plants and human ailments from antiquity and for treatment against viral bacterial and fungal infections [9]. A recent study illustrates the synthesis of stable AgNPs with bioreduction method using $A$. indica (neem) leaf extract, which acted as a reducing agent in green synthesis of AgNPs. The phytochemicals present in neem are namely terpenoids and flavonoids, which act as reducing as well as capping agent and helping in stabilizing the nanoparticles [10].

\section{METHODS}

Preparation of $A$. indica (Neem) leaf extract

Fresh and healthy leaves of neem were identified by the Department of Botany, Kuvempu University and were collected from Shankaraghatta, Shivamogga District, Karnataka, India. About $30 \mathrm{~g}$ of the healthy leaves were washed thoroughly with double distilled water and were boiled with $300 \mathrm{ml}$ distilled water in $500 \mathrm{ml}$ beaker for 30-40 min. The extract was cooled and filtered twice through Whatman no. 1 filter paper to get clear solution [11]. The filter was refrigerated in $250 \mathrm{ml}$ Erlenmeyer flask at $4^{\circ} \mathrm{C}$ for further experimental use.

\section{Synthesis of AgNPs}

$1 \mathrm{mM}$ silver nitrate and leaf extract were taken for the synthesis of AgNPs. $10 \mathrm{ml}$ of leaf extract was added drop by drop using burette to $1 \mathrm{mM}$ silver nitrate solution to achieve the reduction of $\mathrm{Ag}^{+}$ions with continuous stirring on magnetic stirrer [12]. A complete color change was observed and became brown to dark brown after $36 \mathrm{~h}$. The synthesis of AgNPs was further confirmed using UV-spectrophotometer.

\section{Synthesis of copper oxychloride conjugated AgNPs (COC-AgNPs)} The mixture of the fungicide (copper oxychloride $0.1 \%$ ) and neem extract was pre-chilled for $15 \mathrm{~min}$. Along with vigorous stirring on a magnetic stirrer for about 5-10 min, silver nitrate solution was added drop wise to the above mixture. On addition of $15 \mathrm{ml}$ of silver nitrate solution turns dark yellow. 
UV-visible spectroscopy

The optical properties of synthesized AgNPs were determined using UV-visible spectrometry. The UV-visible absorption spectra of AgNPs and COC-AgNPs were observed in the range of 350-450 $\mathrm{nm}$ [9].

\section{Scanning electron microscopy (SEM) analysis}

The SEM analysis is the best method for determining the surface topography and three-dimensional view of the synthesized nanoparticles. The morphological characteristics of AgNPs and COCAgNPs were established by the SEM. Thin films of the samples were prepared on a carbon-coated copper grid by dropping a very small amount of the sample on the SEM grid, and the film was allowed to dry by keeping it under a mercury lamp for $5 \mathrm{~min}$ and then was subjected for the SEM analysis.

\section{X-ray diffraction (XRD) analysis}

The crystallite domain size was calculated from the width of XRD peaks, assuming that they are free from non-uniform strains, using the Scherrer formula.

$\mathrm{D}=0.94 \lambda / \beta \operatorname{Cos} \theta$

Where $\mathrm{D}$ is the average crystallite domain size perpendicular to the reflecting planes, $\lambda$ is the X-ray wavelength, $\beta$ is the full width at half maximum (FWHM), and $\theta$ is the diffraction angle. To eliminate additional instrumental broadening, the FWHM was corrected, using the FWHM from a large grained Si sample. $\beta$ corrected $=\left(\mathrm{FWHM}^{2}\right.$ sample-FWHM $\left.{ }^{2} \mathrm{si}\right)^{1 / 2}$.

The lyophilized AgNPs and COC-AgNPs were coated on the grid and were subjected to XRD measurements. The analysis was carried out using X-ray diffractometer with an operating voltage of $45 \mathrm{kV}$ and a current of $0.8 \mathrm{~mA}$ (Unisantis XMD-300, Swiss). The diffraction patterns were recorded by $\mathrm{Cu}-\mathrm{K} \alpha$ radiation of wavelength $1.54 \AA$ in the region of $2 \theta$ from $0^{\circ}$ to $60^{\circ}$.

\section{Fourier-transform infrared (FTIR) spectroscopy}

The AgNPs, copper oxychloride, and COC-AgNPs were subjected to FTIR spectroscopy (Bruker, USA) to analyze their spectra. The analysis was carried out with potassium bromide pellets, recorded in the range $500-4000 \mathrm{~cm}^{-1}$.

\section{In vitro antifungal activity of AgNPs and COC-AgNPs}

The antifungal activity of AgNPs and COC-AgNPs was investigated by well plate method, in vitro. Different volumes $(25 \mu \mathrm{l}, 50 \mu \mathrm{l}, 75 \mu \mathrm{l}$, and $100 \mu \mathrm{l}$ ) of the synthesized AgNPs and COC-AgNPs were added to wells made in the solidified potato dextrose agar media. The plates were incubated at $35^{\circ} \mathrm{C}$ for $48-72 \mathrm{~h}$ for the visualization of inhibition zones. The inhibition of control (1\% copper oxychloride alone) was also examined along with AgNPs.

\section{RESULTS AND DISCUSSION}

\section{Characterization of AgNPs and COC-AgNPs}

The AgNPs exhibit reddish brown color in aqueous solution due to excitation of surface plasmon vibrations in AgNPs. The reduction of silver ions to AgNPs is indicated by color change and UV-visible spectrum. The addition of copper oxychloride and neem extract during the synthesis of conjugated COC-AgNPs results in change in color of the solution to reddish brown. This can be attributed to weak electrostatic interaction between $\mathrm{Cl}$ atom of copper oxychloride and $\mathrm{Ag}$ atom in AgNPs.

\section{UV-visible spectroscopy}

The UV-visible spectroscopy is one of the most widely used techniques for the structural characterization of AgNPs. The absorption band in 350 to $550 \mathrm{~nm}$ region is typical for the AgNPs [13]. The UV-visible spectra showed absorption bands in 350 to $550 \mathrm{~nm}$ region which confirms the formation of AgNPs [14-16]. In this study, we found that the AgNPs and
COC-AgNPs showed the characteristic absorption peak at $418 \mathrm{~nm}$ and $424 \mathrm{~nm}$, respectively (Fig. 2a and b).

\section{SEM analysis}

Microscopic surface features including morphology and particle size of synthesized AgNPs and COC-AgNPs were assessed by SEM analysis. The nanoparticles were found to be spherical in shape with a diameter ranging from 19 to $24 \mathrm{~nm}$ and 21 to $25 \mathrm{~nm}$, respectively. SEM image also confirms that the synthesized nanoparticles are well separated with no aggregation (Fig. 3a and 3b).

\section{XRD analysis}

The synthesized AgNPs and COC-AgNPs were subjected to XRD studies, to understand the crystallinity and to establish the average particle size. As shown in Fig. 4a, the XRD pattern of AgNPs has prominent diffraction peaks of the $2 \theta$ values of $36.97^{\circ}, 46.02^{\circ}, 62.10^{\circ}$, and $74.47^{\circ}$ which can be assigned to $111,200,220$, and (311) planes, respectively, with some minor peaks [17].

The Fig. 4b, the XRD pattern of copper oxychloride alone showed prominent characteristic peaks of $2 \theta$ at $19.83^{\circ}, 25.54^{\circ}$, and $35.25^{\circ}$ which

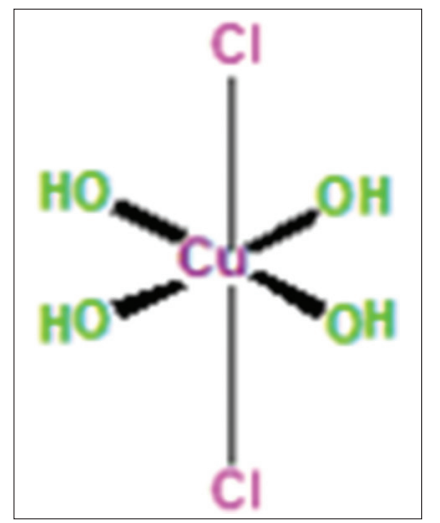

Fig. 1: Structure of copper oxychloride

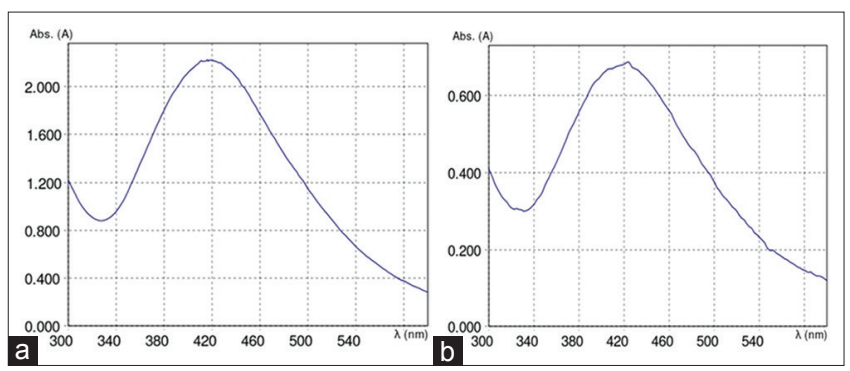

Fig. 2: (a) UV-visible absorption spectra of silver nanoparticles prepared using a biological method. (b) UV-visible absorption spectra of conjugated silver nanoparticles prepared using a biological method

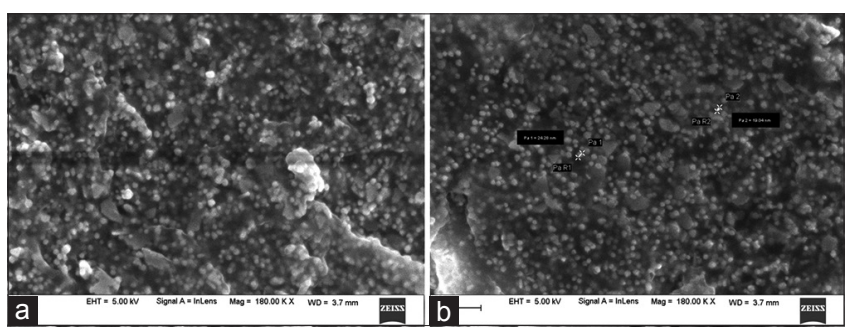

Fig. 3: (a) Scanning electron microscopy (SEM) images of silver nanoparticles. (b) SEM images of fungicide-conjugated silver nanoparticles 


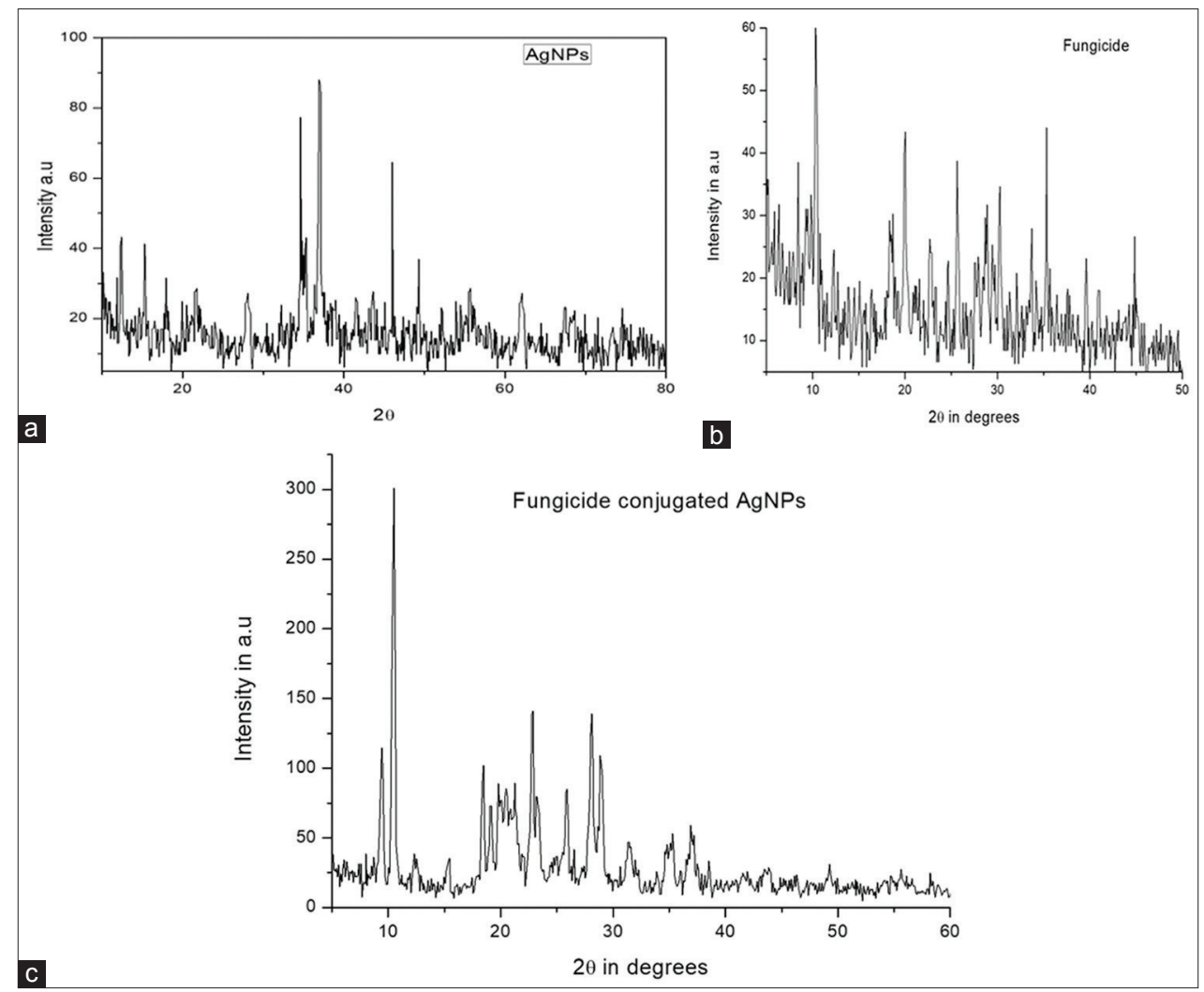

Fig. 4: (a) X-ray diffraction (XRD) pattern of silver nanoparticles (AgNPs). (b) XRD pattern of fungicide copper oxychloride. (c) XRD pattern of copper oxychloride conjugated AgNPs

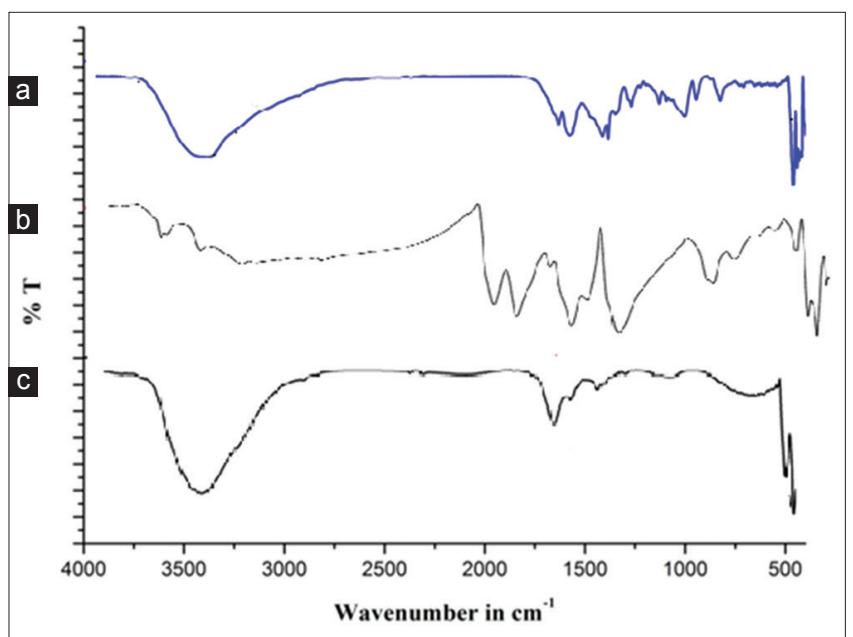

Fig. 5: Fourier-transform infrared spectroscopy of (a) silver nanoparticles (AgNPs), (b) copper oxychloride, and (c) conjugated (AgNPs + copper oxychloride)

confirms the presence of copper oxychloride [18]. The XRD pattern of COC-AgNPs showed characteristic peaks of $2 \theta$ at $18.36^{\circ}, 25.81^{\circ}$, and $34.58^{\circ}$ corresponding to copper oxychloride and the peaks of $2 \theta$ at $36.84^{\circ}, 49.21^{\circ} 61.97^{\circ}$, and $74.60^{\circ}$ corresponding to AgNPs (Fig. 4c). The data confirm that copper oxychloride has been successfully adsorbed on the surface of AgNPs.

\section{FTIR spectroscopy}

The FTIR spectra of synthesized AgNPs showed various absorption bands for different chemical groups (Fig. 5). The broad band at $3384.49 \mathrm{~cm}^{-1}$ showed the stretching vibrations of $-\mathrm{N}-\mathrm{H}$ and $-\mathrm{O}-\mathrm{H}$

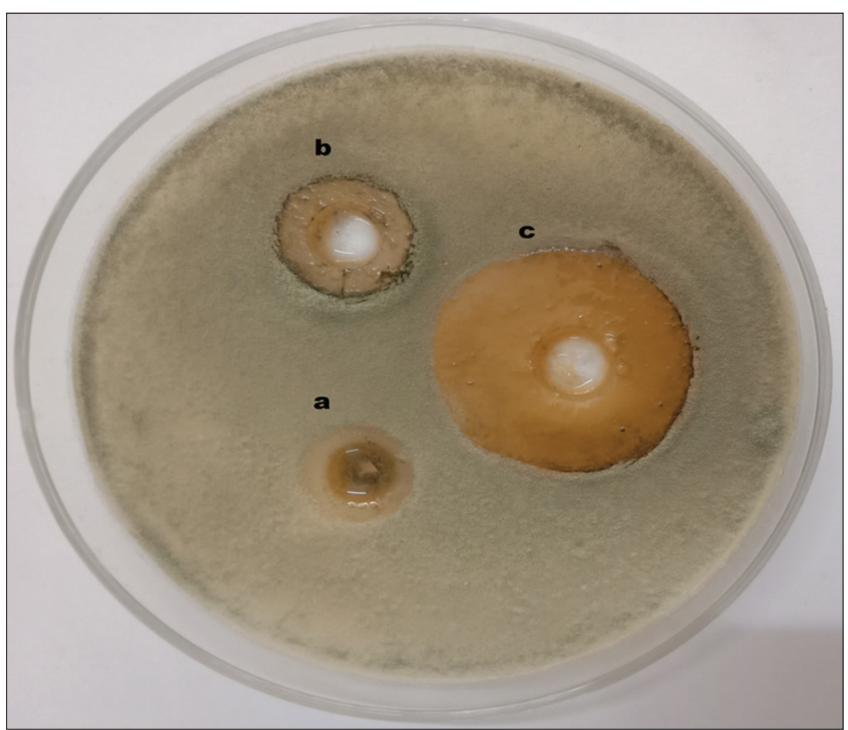

Fig. 6: Antifungal activity of (a) silver nanoparticles (AgNPs), (b) copper oxychloride, and (c) copper oxychloride-conjugated AgNPs by the disc-diffusion method

groups and the absorption bands at $1630.78,1384.50$, and $1002.23 \mathrm{~cm}^{-1}$ correspond to $-\mathrm{C}=\mathrm{O},-\mathrm{C}=\mathrm{C}-$, and $-\mathrm{C}-\mathrm{O}$ groups, respectively. In addition, the presence of absorption band at $1129.74 \mathrm{~cm}^{-1}$ confirms the presence of -C-N group [19].

The FTIR spectrum of copper oxychloride shows characteristic peaks at $1578.31,1301.44$, and $1244.31 \mathrm{~cm}^{-1}$ which confirms the presence of copper oxychloride as shown earlier [20]. The FTIR spectrum of COCAgNPs shows distinct peaks at 3384.49 and $1630.78 \mathrm{~cm}^{-1}$, illustrating 
the stretching vibrations confirms the AgNPs. The peaks at $1578.31 \mathrm{~cm}^{-1}$ establish the adhesion of copper oxychloride on the AgNPs.

\section{Antifungal activity of AgNPs and COC-AgNPs}

The antifungal potential of AgNPs and COC-AgNPs was assessed against C. gloeosporioides which is known to cause anthracnose disease in mangoes. The results illustrate that the inhibition of fungal growth was observed with both AgNPs and COC-AgNPs (Fig. 6). The copper oxychloride $(1 \%)$ significantly inhibited with an inhibition zone of diameter $1.2 \mathrm{~cm}$ which is $50 \%$ more than the AgNPs, which showed the inhibition zone of diameter $0.8 \mathrm{~cm}$. Further, the fungicide-conjugated AgNPs exhibited the highest growth inhibition of $C$. gloeosporioides $(\sim 187 \%)$ as compared to fungicide copper oxychloride alone with an inhibition zone of $2.3 \mathrm{~cm}$. The inhibition of growth was also found to be dose-dependent with respect to the concentration of COC-AgNPs. The comparison of inhibition data shows a high significance when compared between COC-AgNPs and AgNPs $(\mathrm{p}<0.002)$ and copper oxychloride $(\mathrm{p}<0.005)$.

\section{AUTHORS' CONTRIBUTIONS}

Raghu HS has designed the experiments and edited the manuscript, Raghavendra SN and Divyashree K have performed the experiment, and Rajeshwara AN has supervised the experiments.

\section{CONFLICTS OF INTEREST}

All authors have no conflicts of interest to declare.

\section{REFERENCES}

1. Zakawa NN, Channya KF, Magga B and Akesa TM. Antifungal effect of neem (Azadirachta indica) leaf extracts on mango fruit post-harvest rot agents in Yola, Adamawa state. J Pharm Phytochem 2018;7:23-6.

2. Shinde GS, Viradia RR, Patil SA, Kakade DK. Effect of post harvest treatments of natural plant extract and wrapping material on storage behavior of mango (cv. KESAR). Inter J Agric Sci 2009;5:420-3.

3. Mathur A, Kushwaha A, Dalakoti V, Dalakoti G, Singh DS. Green synthesis of silver nanoparticles using medicinal plant and its characterization. Pelagia Res Libr 2014;5:118-22.

4. Rauwel P, Küünal S, Ferdov S, Rauwel E. A review on the green synthesis of silver nanoparticles and their morphologies studied via TEM. Adv Mater Sci Eng 2015;2015:9.

5. Mavani K, Shah M. Synthesis of silver nanoparticles by using sodium borohydride as a reducing agent. In J Eng Res Technol 2013;2:1-5.

6. Richardson HW, editor. In: Handbook of Copper Compounds and Applications. New York, U.S.A: Marcel Dekker, Inc.; 1997. p. 71

7. Lubej A, Koloini T, Pohar C. Industrial precipitation of cupric hydroxysalts. Acta Chim Slov 2004;51:751-68.

8. Gavhane AJ., Padmanabhan P, Kamble SP, Jangle SN. Synthesis of silver nanoparticles using extract of neem leaf and triphala and evaluation of their antimicrobial activities. Int J Pharm Bio Sci 2012;3:88-100.

9. Ahmed S, Saifullah, Ahmad M, Swami BL, Ikram S. Green synthesis of silver nanoparticles using Azadirachta indica aqueous leaf extract. J Radiat Res Appl Sci 2016;9:1-7.

10. Verma A, Mehata MS. Controllable synthesis of silver nanoparticles using neem leaves and their antimicrobial activity. J Radiat Res Applied Sci 2016;9:109-15.

11. Girish K, Neem (Azadirachta indica a. Juss) as a source for green synthesis of nanoparticles. Asian J Pharm Clin Res 2018;11:15-8.

12. Geoprincy G, Sri BN, Poonguzhali U, Gandhi NN, Renganathan S. A review on green synthesis of silver nanoparticles. Asian J Pharm Clin Res 2013;6 Suppl 1:8-12.

13. Aslan K, Lakowicz JR, Geddes CD. Rapid deposition of triangular silver nanoplates on planar surfaces: Application to metal-enhanced fluorescence. J Phys Chem B 2005;109:6247-51.

14. Sastry M, Mayya KS, Bandyopadhyay K. pH dependent changes in the optical properties of carboxylic acid derivatized silver colloidal particles. Colloids Surf A 1997;127:221-8.

15. Henglein A. Physicochemical properties of small metal particles in solution: 'Microelectrode' reactions, chemisorption, composite metal nparticles, and the atom-to-metal transition. Phys Chem B 1993;97:5457-71.

16. Sastry M, Patil V, Sainkar SR. Electrostatically controlled diffusion of carboxylic acid derivatized silver colloidal particles in thermally evaporated fatty amine films. Phys Chem B 1998;102:1404-10.

17. Liang, FH, Yong GX, Yuan ZZ, Min MA. Study on the crystalline structure and thermal stability of silver oxide films deposited by directcurrent reactive magnetron sputtering methods. J Korean Phys Soc 2010;56:1176-9.

18. Yu Y, Chu X, Pang G, Xiang Y, Fang H. Effects of repeated applications of fungicide carbendazim on its persistence and microbial community in soil. J Environ Sci (China) 2009;21:179-85.

19. Bahrami-Teimoori B, Nikparast Y, Hojatianfar M, Akhlaghi M, Ghorbani R, Pourianfar HR. Characterization and antifungal activity of silver nanoparticles biologically synthesised by Amaranthus retroflexus leaf extract. J Exp Nanosci 2017;12:129-39.

20. Bai C, Zhang S, Huang L, Ye Q. Starch-based hydrogel loading with carbendazim for controlled-release and water absorption. Carbohydr Polym 2015;125:376-83. 